“Transfer” XVI: 1-2 (2021), pp. 153-157. ISSN: 1886-5542

\title{
COLABORADORES DE ESTE NÚMERO
}

CAMPS, Assumpta - Catedrática de Filología Italiana de la Facultad de Filología y Comunicación en Universidad de Barcelona (UB). Sus líneas de investigación son los Estudios de Traducción, la Recepción de la Literatura Italiana en el ámbito hispánico, y la Literatura Italiana Contemporánea. Es autora de varios volúmenes, entre los que destacan Recepción de Gabriele D'Annunzio en Cataluña, 2 vols. (1996-1999); Studi critici di letteratura italiana contemporanea (2003), Italia-España en la época contemporánea. Estudios críticos sobre la traducción y recepción literarias (2009), El Decadentismo italiano en la literatura catalana (2010), Italia en la prensa periódica durante el franquismo (2014), Traducción y recepción de la literatura italiana (2014) y La traducción en la creación del canon poético. Recepción de la poesía italiana en el ámbito hispánico en la primera mitad del siglo XX (2015). Entre los libros que ha editado, mencionaremos Literary Translation in the Contemporary Age (2008), Translation and Multiculturality (2008) y La traducción en las relaciones ítalo-españolas: lengua, literatura y cultura (2012). Es también autora de más de un centenar de artículos y comunicaciones en congresos, mayoritariamente de ámbito internacional; así como coordinadora del "CRET - Grup de Recerca Consolidat sobre Estudis de Traducció i Multiculturalitat" (UB); y directora de la revista bilingüe (español/inglés) "TRANSFER, e-journal on Translation and Intercultural Studies", creada en 2006 y reconocida como revista científica de la UB. Ha formado parte del Comité Ejecutivo de la "International Comparative Literature Association" (ICLA) durante años (2004-2010), y desde 2013 es Vicepresidenta del "Translation Committee" de dicha asociación internacional.

COGLIANO, Bianca - Graduada en Literatura Moderna: estudios italianos. Máster, con matrícula de honor, en la Universidad de Roma La Sapienza. Trabajo de fin de máster sobre Luisa Adorno y 
“Transfer” XVI: 1-2 (2021), pp. 153-157. ISSN: 1886-5542

sus obras cuyo título es: "Luisa Adorno: la dimensione della guerra attraverso la memoria". Materia de investigación: la literatura de género. Actualmente está cursando un doctorado en la Universidad de Sevilla, línea de investigación "Mujer, escrituras y comunicación", con el proyecto de investigación: "Lando Ortensio en la Querelle des Femmes" cuya directora de tesis es Mercedes Arriaga Flórez. Por su segundo año de doctorado (2019/2020) ha obtenido una beca de perfeccionamiento de la Universidad de Roma La Sapienza para su trabajo de investigación con el grupo "Escritoras y Escrituras" (HUM753).

CROLLA, Adriana Cristina - Cavaliere dell' Ordine della Stella d'Italia (Presidenza dello Stato Italiano, 2015). Magister en Docencia Universitaria (UNL). Profesora de Letras y de Italiano (UNL y UADER). Directora del Portal Virtual de la Memoria Grin-ga, del Programa de Estudios sobre Migraciones y del Labo-ratorio de Materiales Orales (www.fhuc.unl. edu.ar/portalgringo). Directora del Centro de Estudios Comparados y de la revista El hilo de la fábula. Premio «Piemontesi nel Mondo» por la Regione Piemonte, Italia, 2012; Premio «Espacio Santafesino 2012» Gob. de Santa Fe por el proyecto Altrocché!: espacios de la italianidad en la cultura santafesina. Autora, editora y traductora de veinte libros y más de 80 artículos. Publicaciones relacionadas con la italianística (como editora): Olor a Lluvia (Odore di pioggia), de Rodolfo Alonso-Trad. Giuseppe Mascotti (UNL, 2018); Fortunato E. Nari. Cantata de las ceremonias y otras cosmogonías. (UNL, 2017); Mario R. Vecchioli. Una pipa, Una gesta y la reiteración de la poesía (UNL, 2016); Italia y Francia en Santa Fe. diversidades, legados y reconfiguraciones (UNL, 2015); Altrocché! Italia y Santa Fe en diálogo (UNL, 2014); (como autora): Leer y enseñar la italianidad. Sesenta años y una historia en la Universidad Nacional del Litoral (UNL, 2013); (como directora): Las migraciones italo-rioplatenses Memoria cultural, Literatura y Territorialidades (UNL, 2013), accesible on line: (www.fhuc.unl.edu.ar/.../crear/.../Las_migraciones_italo_rioplaten ses.pdf; (como compiladora): Realidad y fantasía - Cine y literatura. Italia en el laberinto de sus múltiples moradas (ADILLI - UNL, 
“Transfer” XVI: 1-2 (2021), pp. 153-157. ISSN: 1886-5542

2005); VIII Congreso de Lengua y Literatura Italiana. (Comp. UNL, 1992); (como traductora y compiladora): La piel desnuda. Poetas italianas entre milenios (Laborde, 2001).

DELLA ROCCA, Alessia - Se graduó con matrícula de honor en Civilizaciones y Lenguas Extranjeras Modernas en la Università degli Studi di Parma y en Interpretación y Traducción Especializada, en el curso de Máster de la Università degli Studi Internazionali di Roma en los idiomas francés, inglés y español.

FRANZOSO, Marco - Obtuvo los títulos de Laurea Magistrale in Lingue e Letterature Europee, Americane e Postcoloniali de la Università Ca' Foscari de Venecia, y de Licenciado en Letras por la Universidad Nacional del Litoral (UNL). Desde el año 2014 investiga -en el marco de proyectos del Centro de Estudios Comparados de la U.N.L- autores y temas relacionados con la literatura comparada, la literatura de migración, y en particular las culturas italiana y argentina en contacto. Otras áreas de interés son el cine y el arte latinoamericano y europeo. Es colaborador lingüístico de la revista EL HILO DE LA FÁBULA. Forma parte del Portal Virtual de la memoria Gringa y del Laboratorio de Materiales Orales de FHUC-UNL. Actualmente realiza el Doctorado en Humanidades con orientación en Letras de la UNL. Su tesis doctoral estudia la trayectoria intelectual de Fernando Birri.

MATURANA, Andrea - Graduada en Lenguas y Literaturas Modernas en la modalidad de inglés y francés por la Universitat de Barcelona. Actualmente está cursando el Máster en Traducción Profesional inglés-español de la Universitat Rovira i Virgili. Tras haber pasado un año trabajando en Francia con una beca de auxiliar de conversación del Ministerio de Educación, compagina sus estudios con el trabajo de profesora, transcriptora y traductora.

MONTERO DOMÍNGUEZ, Xoán - Doctor en Traducción e Interpretación por la Universidade de Vigo, donde desarrolla su labor do- 
“Transfer” XVI: 1-2 (2021), pp. 153-157. ISSN: 1886-5542

cente. Además de haber publicado artículos sobre traducción audiovisual y normalización lingüística en revistas científicas de ámbito nacional e internacional, es autor del libro La traducción de proyectos cinematográficos. Modelo de análisis para los largometrajes de ficción gallegos (Peter Lang, 2015) y editor de los volúmenes Traducción para la comunicación internacional (Comares, 2013), Traducción e industrias culturales. Nuevas perspectivas de análisis (Peter Lang, 2014), El doblaje. Nuevas vías de investigación (Comares, 2017) e Intérpretes de cine. Análisis del papel mediador en la ficción audiovisual (Peter Lang, 2019).

VALENCIA, María Dolores - Catedrática de lengua y literatura italiana de la Universidad de Granada. Está especializada en el estudio de la literatura barroca italiana, especialmente en la lírica marinista y antimarinista (destaca, en este sentido, su obra $T$. Stigliani. Lo scherzo di Parnaso. Contribución al estudio del antimarinismo. Estudio, edición y notas, Granada: EUG, 1987), las relaciones entre el literato y el poder político ("Tommaso Stigliani o l'ubiquità del letterato di corte nel Seicento italiano", en Scrittura e potere, Roma: Bulzoni, 2010) o la preceptiva métrica ("Métrica y poesía en la Italia del Seicento: notas al Arte del verso italiano de Tommaso Stigliani”, en Filologia e critica nella modernità letteraria. Studi in onore di Renzo Cremante. Bologna: CLUEB, 2012). Colabora en revistas especializadas y es autora asimismo de unmerosos ensayos de literatura italiana contemporánea sobre Pirandello, Papini, Borgese, Bontempelli, Bufalino y Paola Baronchelli, entre otros. Además, se ha ocupado de la traducción literaria en el volumen Seis estudios sobre la traducción en los siglos XVI y XVII (en colaboración con J.A. Sabio), Granada: Ed. Comares, 2003, es autora de la traducción de Tiro al piccione de Giose Rimanelli (Granada: EUG, 2002) y de la Malora de Beppe Fenoglio (Madrid: Huerga \& Fierro Editores, 2006).

VERCHER GARCÍA, Enrique J. - Profesor en la Universidad de Granada en la etapa 2004-2019 y actualmente Profesor Ayudante Doctor en la Universidad Complutense de Madrid. Es también 
“Transfer” XVI: 1-2 (2021), pp. 153-157. ISSN: 1886-5542

investigador, traductor y escritor. Doctor en Ciencias de la Traducción (Universidad de Bolonia) y en Filología Eslava (Universidad de Granada, Premio Extraordinario de Doctorado), así como Licenciado en Filología Hispánica (Universidad de Granada), Filología Eslava (Universidad de Granada, Premio Nacional de Licenciatura) y Ruso como Lengua Extranjera (Universidad Estatal de San Petersburgo). Ha desarrollado su labor docente e investigadora en Rusia, Italia, Reino Unido y España. Es autor de numerosas monografías y artículos en el campo de la Filología y la Traducción. Es miembro de los grupos de investigación HUM-0417 "Investigaciones de Filología Eslava" y 970844 Estudios Rusos Complutenses: Lengua, Literatura, Cultura, Religión, Política y Sociedad y ha participado en diversos proyectos de investigación. Sus campos principales de investigación y docencia son la Eslavística, la Lingüística Comparada Ruso-Española, Modalidad y Valoración Lingüísticas, la Traductología y Traducción de Culturemas, la Linguo-culturología, la Enseñanza de la Lengua Rusa, la Enseñanza Multidisciplinar de las Literaturas Eslavas, los Estudios Culturales, la Poesía Actual Rusa y la Semiótica Literaria. 